Article

\title{
Primary Stability of Temporary Screws after Dentary and Orthopedic Forces under Static and Dynamic Load Cycles
}

\author{
Daniel J. Fernandes ${ }^{1, *,+}{ }^{+}$, Flavia A. Barbosa ${ }^{2}$, Ligia M. Ferreira ${ }^{1}$ and Carlos N. Elias ${ }^{1}$ \\ 1 Laboratory of Biomaterials, Instituto Militar de Engenharia, Rio de Janeiro RJ 22290-270, Brazil; \\ ligliu@hotmail.com (L.M.F.); elias@ime.eb.br (C.N.E.) \\ 2 Master Program in Dentistry, Universidade São Leopoldo Mandic, Rio de Janeiro RJ 22221-070, Brazil; \\ fabarbosa@hotmail.com \\ * Correspondence: djfernandes@ime.eb.br; Tel.: +55-21-2546-7080 (ext. 6848); \\ † Current address: Praça General Tibúrcio, 80/sala 2030, Praia Vermelha, Rio de Janeiro RJ 22290-270, Brazil.
}

Academic Editor: João Manuel R. S. Tavares

Received: 28 December 2016; Accepted: 16 February 2017; Published: 3 March 2017

\begin{abstract}
The objective was to analyze the influence of dentary and orthopedic forces under static and dynamic loads in temporary screw stability. Self-drilling titanium (Ti6Al4V) screws $(6 \times 1.5 \mathrm{~mm})$ were inserted and removed from pig ribs. Screws were loaded by static loads of $2 \mathrm{~N}$ and $5 \mathrm{~N}$ for 5 weeks. Dynamic force was applied during 56,000 cycles for simulations of a patient's opening-closing mouth movements. Dynamic applied loads ranged from 2 to $5 \mathrm{~N}$ and from 5 to $7 \mathrm{~N}$ under a frequency of $1 \mathrm{~Hz}$. Torque peak values at placement and removal were measured before and after static and dynamic cycles. Similarities in torque peaks $(p=0.3139)$ were identified at placement $(12.54 \mathrm{Ncm})$ and removal $(11.2 \mathrm{Ncm})$ of screws after a static load of $2 \mathrm{~N}$. Statistical comparisons showed significant stability loss after dynamic cycles under loads of $2 \mathrm{~N}(64.82 \%$ at $p=0.0005)$ and $5 \mathrm{~N}(64.63 \%$ at $p=0.0026)$. Limited stability loss occurred in temporary screws submitted to $2 \mathrm{~N}$ static forces $(p=0.3139)$. The detrimental effects of dynamic cycles in temporary screws stability was attested after the simulation of dentary and skeletal forces, being intermittent forces more relevant in the loss of mechanical stability.
\end{abstract}

Keywords: temporary screws; stability; torque; titanium; biomechanics

\section{Introduction}

Temporary screws are multi-purpose devices used in different specialities of medical sciencesand dentistry [1-3]. Titanium alloys have excellent corrosion resistance and adequate mechanical properties, for applications as permanent devices in orthopedic spine surgeries or for temporary use in the biomechanics involving the dental movements.

The selection of the adequate alloy is based on its application, including a commercially pure titanium choice when osseointegration is desired or another types of titanium alloys when just a temporary implantation period is planned. Because these devices are outlined for a limited period, the primary stability is prioritized instead of the osseointegration potential.

Satisfactory mechanical interlocking can be attained if a suitable balance is accomplished among screws design, host architecture and technical factors, which include surgeon's expertise. Screw design is dependent of threads and its diameters, shape (geometry, depth, and pitch), self-drilling or self-tapping ability and screw body that might have tapered or cylindrical shape $[4,5]$. Regarding influence of host tissue in stability, it is mainly ruled by bone features, its elastic modules compatibility with screw alloy, and the thickness, quality and density of cortical and cancellous bone. Lekholm and Zarb organized jaw bone tissue in four types, in coherence with its thickness, density, and quality [6]: 
Bone D1, mainly homogeneous compact cortical bone; D2, a thick layer of compact cortical bone surrounding a dense trabecular bone core; D3, a thin layer of cortical bone bordering a lower dense trabecular bone core; and D4, a thin layer of cortical bone surrounding a reduced-density trabecular core.

The influence of cortical bone thickness into the primary stability was attested by different authors in terms of screw-bone interlocking [7-9]. Although a positive correlation was identified between cortical thickness and primary stability, an excessive thick and dense cortical thickness can contribute to screw failure [7]. In maxillofacial region, different works showed that failures in temporary screws due to its stability loss occurred when screws were placed in the thickest and densest cortical areas available, as observed in the posterior buccal region of a mandible [10-13]. Innumerous works used placement torque as an adequate method to evaluate the immediate stability after screw insertion $[4,5,14-18]$.

The advantages of temporary screws for dentary demand is presented in [11-20]. When tooth movements are desired, screws allow immediate possibility for biomechanical forces applications, which include even pull back of more than 10 teeth at once [21]. For multiple teeth movements, some biomechanic solutions involve the application of cyclic loads by the activation of elastomers connected from one jaw to a temporary screw placed on the other jaw. Although this condition represents an unexceptional situation for biomechanics, from our knowledge the effects of dynamic load cycles in temporary screws stability has never been evaluated by a model that mimics the opening and closing movements of patient's mouth. The objective of this work evaluates the temporary screw primary stability when submitted to dentary and orthopedic forces under dynamic and static load cycles.

\section{Materials and Methods}

Similar method was previously disclosed in the preliminary experimentations of this work published in a pilot study [19].

Forty temporary self-drilling titanium grade 5 (Ti-6Al-4V) screws (Conexão Sistema de Próteses, Arujá, SP, Brazil) were divided into groups, whereas static, dynamic and no loads were applied. The groups were labeled as static $(n=20)$, dynamic $(n=10)$, or control $(n=10)$ and were separated according to the magnitude of the forces applied. Forces with magnitude of $2 \mathrm{~N}$ and $5 \mathrm{~N}$ were considered as dentary and orthopedic, respectively. Control screws were not loaded and were able to attest any influence of rib bones inhomogeneity into screw stability. All screws had the same taper design and dimensions: $6 \mathrm{~mm}$ long and $1.5 \mathrm{~mm}$ at maximum diameter (Figure 1). Sample size calculations, details of bone blocks preparation and statistical comparisons were all detailed in the pilot study published as [19].

Forty self-drilling screws were attached with a perpendicular orientation into ribs following a 1.0-mm-diameter pre-drilled hole at a speed of $5 \mathrm{rpm}$, until the transmucosal profile of the screw neck contacted the cortical surface. The procedure was in accordance with ASTM F117 (ASTM F117, Test Method for Driving Torque of Medical Bone Screws) and F543 (F543-13e1, Standard Specification and Test Methods for Metallic Medical Bone Screws). The same protocol was used in [9]. Placement and removal torque peaks were measured with a digital torquemeter (Lutron TQ-8800, Taipei, Taiwan).

In static groups, 10 samples of two screws were attached into pig ribs at a distance of $20 \mathrm{~mm}$. A $6.0 \mathrm{~mm}$ long stainless steel close spring was stretched until a $2 \mathrm{~N}$ and $5 \mathrm{~N}$ was applied to screws. The force was measured by a digital data collection module Pasco Xplorer GLX PS-2002 (Pasco scientific, Roseville, CA, USA). The static load was maintained for 5 weeks (Figure 2) in order to simulate the time period expected between consecutive clinical appointments. The static load applied to screws were able to reproduce the moments imposed during a different range of orthodontic movements addressed directly to the screw head. 


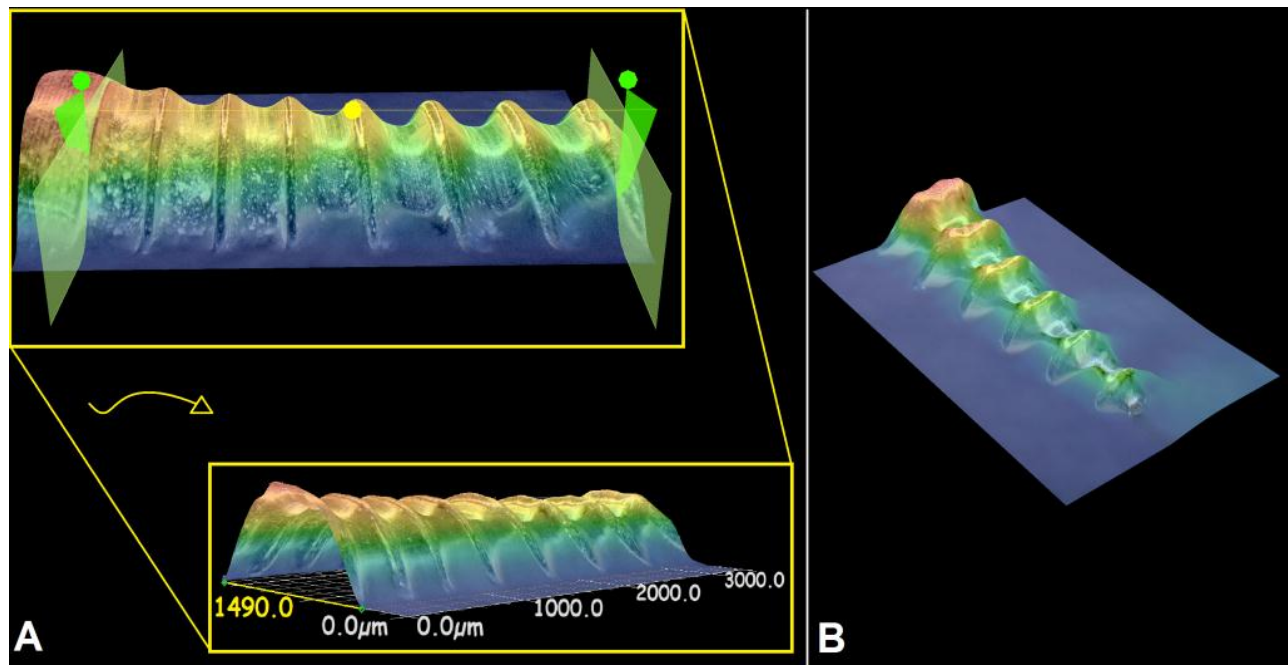

Figure 1. Temporary screws design. (A) Screws were tapered with a minor diameter of $1.5 \mathrm{~mm}$ and a length of $6 \mathrm{~mm}$. (B) Threads had self-drilling ability.

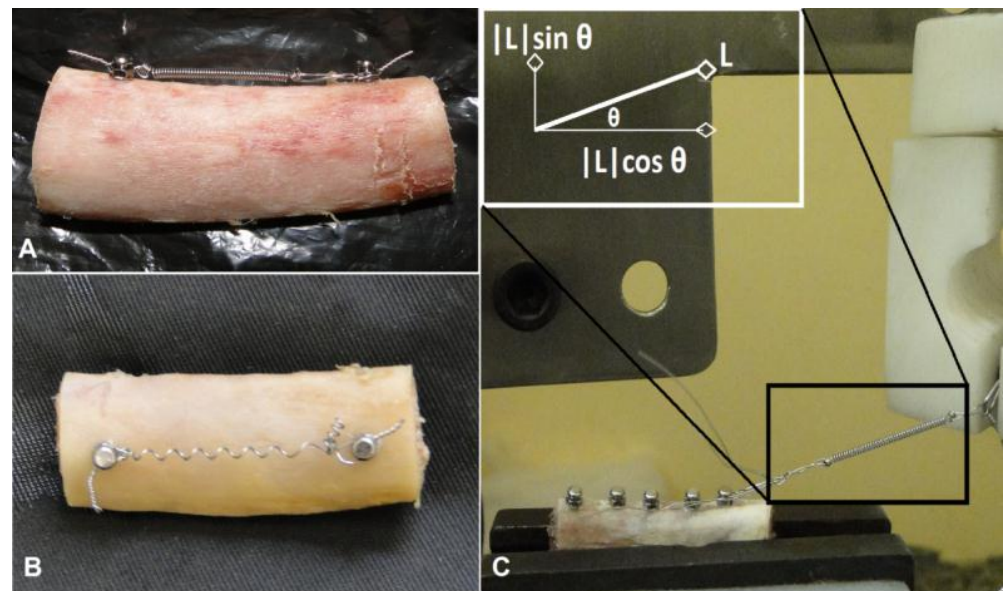

Figure 2. Static load of $2 \mathrm{~N}$ (A), static load of $5 \mathrm{~N}$ (B) applied for 5 weeks and dynamic (C) loads in temporary screws attached in pig rib bones. Vertical (pull out) and horizontal (pulling) components of the dynamic load $(L)$, and the angle $(\theta)$ between $L$ and a horizontal baseline, are shown. $\theta$ was $10^{\circ}$ during closed mouth and $15^{\circ}$ during opened mouth simulations. I L I was in range of 2-5 N and 5-7 N. Static load remained stable for 5 weeks at $2 \mathrm{~N}$.

In dynamic groups, 10 screws were placed into pig ribs at a distance of $15 \mathrm{~mm}$ from each other. A mechanical machine was developed to simulate opening-closing mouth movements by up-and-down axial movements. The loads before cycles were measured by a digital data collection module Pasco Xplorer GLX PS-2002 (Pasco scientific, Roseville, CA, USA) in a range of 2-5 N and 5-7 N under extension for groups of $2 \mathrm{~N}$ and $5 \mathrm{~N}$, respectively. Dynamic loads were applied at an angle of $10^{\circ}$ and $15^{\circ}$, during simulations of mouth closed and opened, respectively. A total of 56,000 cycles were applied to each screw, at a frequency of $1 \mathrm{~Hz}$, in order to reproduce the amount of patient's mouth movements referred to a time period of 5 weeks (Figure 2). In both groups, placement and removal torque were measured, as a reference of the screw stability before and after static and dynamic loads. The dynamic load was able to reproduce intermittent forces if the screws were used to anchorage intermaxillary mechanics. 


\section{Results}

Table 1 and Figure 3 show placement and removal mean peak torque values after static and dynamic forces, from loads of $2 \mathrm{~N}$ and $5 \mathrm{~N}$. The placement torque $(12.54 \pm 1.75 \mathrm{Ncm})$ of the screws after a static load of $2 \mathrm{~N}$ for 5 weeks was a slightly higher than the removal torque $(11.2 \pm 3.37 \mathrm{Ncm})$, without statistical significant difference in that reduction $(p=0.3139)$. After a static force of $5 \mathrm{~N}$, the torque peak was reduced from $15.03 \pm 2.96 \mathrm{Ncm}$ at placement to $7.18 \pm 3.23 \mathrm{Ncm}$ during screw removal (at $p=0.0025$ ). In the control group, differences were observed when comparing placement and removal torque values at $p=0.0007$. No differences were identified in placement torque values comparison between control group and all the other groups evaluated at $p>0.05$.

Table 1. Torque peak mean values $(\mathrm{Ncm})$ and standard deviation from screw placement and removal after static and dynamic forces, with loads of $2 \mathrm{~N}$ and $5 \mathrm{~N}$.

\begin{tabular}{cccccc}
\hline \multirow{2}{*}{ Load } & \multirow{2}{*}{ Control } & \multicolumn{2}{c}{$\mathbf{2 ~ N}$} & \multicolumn{2}{c}{$5 \mathbf{~ N}$} \\
\cline { 1 - 4 } \cline { 4 - 6 } Torque & & Static & Dynamic & Static & Dynamic \\
\hline Placement & $12.95(1.55)$ & $12.54(1.75)$ & $18.14(4.14)$ & $15.03(2.96)$ & $10.18(1.17)$ \\
Removal & $8.3(1.76)$ & $11.2(3.37)$ & $6.38(2.01)$ & $7.18(3.23)$ & $3.6(2.22)$ \\
\hline
\end{tabular}

ANOVA with Tukey's multiple comparisons were applied at $p<0.0001$. Statistical difference was also seen in paired $t$-test comparisons after dynamic load of $2 \mathrm{~N}(p=0.0005)$ and $5 \mathrm{~N}(p=0.0026)$. The influence of different magnitude of forces was not confirmed by $t$-test comparisons between removal torque of both static $(p=0.0518)$ and dynamic loads $(p=0.7223)$. No differences in placement and removal torque peak values were seen between static $(p>0.05)$ and dynamic groups $(p>0.05)$ and the control group. A difference was identified between insertion and removal torque and the control group $(p=0.0007)$, which disclosed an influence of changes in bone architecture after screw attachment.
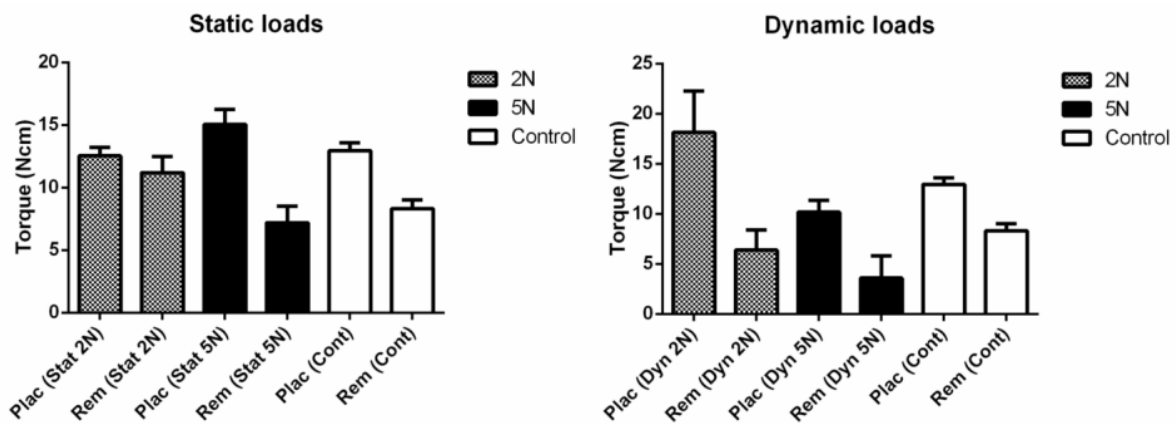

Figure 3. Mean peak torque values $(\mathrm{Ncm})$ after static and dynamic loads cycles. The control group showed placement torque to identify any influence of pig rib bones on stability of the different screws evaluated.

Dynamic cycles imposed significant reductions in torque means at $p=0.0005$ after loads of $2 \mathrm{~N}$ and at $p=0.0026$ after a $5 \mathrm{~N}$ load. The placement torque $(18.14 \pm 4.14 \mathrm{Ncm})$ was higher than the removal torque $(6.38 \pm 2.01 \mathrm{Ncm})$ after $2 \mathrm{~N}$ loads; and a reduction from $10.18 \mathrm{Ncm} \pm 1.17 \mathrm{Ncm}$ to $3.6 \pm 2.22 \mathrm{Ncm}$ was seen after $5 \mathrm{~N}$ loads. The components of the dynamic forces applied were presented in Figure 2. They were showed in terms of vertical and horizontal orientations, and were decomposed based on the angle $(\theta)$ formed between the dynamic load vector $(\bar{L})$ and a horizontal reference baseline. The $\theta$ angle settled at $10^{\circ}$ and $15^{\circ}$ during mouth simulations for closed and opened situations, respectively. The two components of dynamic force $(|L|)$ were exposed in terms of $|L|$.sin $\theta$ for the vertical (pull out force) component and $|L| \cdot \cos \theta$ for the horizontal (pulling force) component. Calculations indicated that just $17 \%-25 \%$ of the applied forces were available at vertical orientation (pull-out component) while 
96\%-98\% of the applied $(|L|)$ force were available at horizontal (pulling forces) orientation during closed and opened mouth simulations in dynamic cycles.

Based on the removal torques, differences were identified only in screws submitted to loads at $2 \mathrm{~N}(p=0.0179)$. Screws loaded at $5 \mathrm{~N}$ revealed similarities in removal torque after static and dynamic cycles ( $p=0.0661$ ). Analogies between removal torques after loads of $2 \mathrm{~N}$ and $5 \mathrm{~N}$, under the same type of force regime (static or dynamic), showed similarities after static $(p=0.0518)$ and intermittent (dynamic cycles) forces $(p=0.7223)$.

\section{Discussion}

The primary stability of temporary screw is a reference of the mechanical interlocking attained between screw surface and bone architecture. This torsional moment is analyzed in terms of the placement torque, mainly in situations where a non-osseointegration device response is planned for temporary purposes $[4,5,15-18,22-25]$. In this work, torque values were measured before and after two different loads conditions with different intensities. The magnitude of the applied forces are in accordance with dentary and orthopedic demand for clinical needs.

Dentary loads handled by stainless steel springs are a common application for biomechanics when a tooth movement is desired, instead of using another tooth as backing. The mechanics can be supported by different devices, from elastomers linked to temporary screws, through headgear appliances when greater forces are needed [21,26,27]. We selected stainless steel springs only to minimize the force loss commonly observed during polymers degradation. The load proposed $(2 \mathrm{~N})$ is in accordance with literature for a movement of a group of 3-4 teeth; commonly, a temporary screw is suggested to achieve faster results for improvements in dental treatment progress. A load at $5 \mathrm{~N}$ is adequate where orthopedic results are demanded.

Although bone turnover could not be simulated from this work, the results collected by the insertion and removal torque after static loads of $2 \mathrm{~N}$ showed the maintenance of the primary stability achieved after a screw placement at $p=0.3139$ [28]. The insertion torque was also considered relevant information on the quality of bone, as shown in studies of $[15,29]$. On the other hand, $5 \mathrm{~N}$ forces as a static load imposed a significant loss of stability after 5 weeks since a reduction of $52.22 \%$ was observed. The significance of this reduction was confirmed by a paired $t$-test at $p=0.0025$. Hence, clinicians must be cautious when planning a load beyond the limits tested in this work. The maintenance of the screw stability after 5 weeks under an immediate static load of $2 \mathrm{~N}$ demonstrated an adequate device stability to support grouped teeth movements during dental treatments. The screw placement torque of the present work was in line with the literature and was considered safe to prevent the transmission of excessive strains and the appearance of cracks, which contribute to the reduction of the device stability $[4,30]$.

The choice of pig ribs as bone sources for screw placement was justified in [19]. Even though a low-density bone source was selected, a pilot hole $1 \mathrm{~mm}$ in diameter was to prevent any kind of crack formation in the cortical shell [19,31-34].Authors decided to perform pilot holes to prevent the propagation of cracks, which would be intensified by the different load protocols proposed in this work.

The dynamic cycles proposed in this work simulated the routine of patient's opening-closing mouth, in which cycles impose relevant loads onto screws. Forces were in magnitude range from $2 \mathrm{~N}$ (mouth closed) through $5 \mathrm{~N}$ (mouth opened). The relevance of this simulation is coherent with intermaxillary biomechanics, when a huge block of teeth, or even an entire jaw, is desired to be moved. Examples of these biomechanics were presented in $[27,35]$ and this method was preliminary tested in the pilot study of this work [19]. Currently available appliances involve the use of several springs, which can be accessible on $[19,36,37]$.

The possibility of bone quality, density variation, and its influence on the placement torque were appraised by a statistical test, whereas multiple comparisons of insertion torque peak values were performed among all groups. Comparisons were established taking into account the different distances 
among the screw positions in each testing group, whereby the two outer screws from the control group were compared just with static load group, while the three central screws were confronted with devices in the dynamic load group. Despite the different comparisons, the complex architecture of the cortical shell and cancellous matrix enforced differences in bone behavior regarding stability of control screws when they were removed ( $p=0.0007)$. However, when comparing the placement and removal torque values from control screws with screws from $2 \mathrm{~N}$ and $5 \mathrm{~N}$ groups separately, no differences were detected at $p>0.05$. These similarities in torque values have disclosed an acceptable homogeneity in the bone sources from the different groups evaluated. The use of ribs was also observed in [30] and supported our decision to use the ribs as bone sources in all testing groups.

After dynamic loading, a detrimental effect in primary stability was seen due to the reduction of the removal torque in paired comparisons with the placement torque measured before the cycles. This result shows the main role of the pulling forces in the screw stability under dynamic cycles, which condition was not observed after static loads of $2 \mathrm{~N}$ for 5 weeks. Different works have simulated the same conditions of the static loads applied by opened springs between two temporary screws in laboratory and in vivo in animals and humans [26,38-40]. The same absence of statistical significance $(p=0.3139)$ of the static load influence on stability was disclosed in $[38,40]$. Çehreli and Arman-Ozçirpici ranked insertion torque values in different ranges according to clinical needs, the values lower than $5 \mathrm{Ncm}$ being considered poor for clinical applications [41]. The values of our removal torque after dynamic loads of $5 \mathrm{~N}$ were below $5 \mathrm{Ncm}(3.6 \pm 2.22 \mathrm{Ncm})$, which demonstrated the detrimental effect of the intermittent loads applied by the dynamic cycles in the primary stability of the temporary screws. This approach was preliminary showed in the pilot study [19] and is corroborated by our results. However, the influence of vertical component was limited (just 15\%-17\% of the dynamic load), the strain distribution was not uniform throughout the bone-screw interface [42]. This statement is in agreement with [43], whereas several factors that interfere with the holding strength of a screw was discussed [43]. Based on these factors, we considered that the pull out parameters might be compared with our dynamic load protocol, since the continuous cycles applied also have a vertical component. Only the intermittence of the dynamic load had not been considered previously in literature regarding pull out strengths, and we believe that is one of the major reasons of the significant decrease in screw primary stability after dynamic load cycles.

Figure 2 showed that the dynamic loads into screw stability can be decomposed in two vectors, based on the angle between the load direction and a bottom baseline. This analysis was entirely discussed in the angle resulted from the load application direction ranging from $10^{\circ}$ (closed mouth simulation) to $15^{\circ}$ (open mouth situation). From this perspective, the pull out influence is limited, since the value of the sine influence is $17 \%-25 \%$ smaller than the entire applied load $(|L|)$. The horizontal component represented by cosine had an influence of $96 \%-98 \%$ from the $|L|$ force applied. Therefore, if a $5 \mathrm{~N}$ load was transferred to screws, only $0.85-1.25 \mathrm{~N}$ resulted in a vertical orientation, while $4.5-4.8 \mathrm{~N}$ were transmitted, pulling the screw in a horizontal direction. Different works have considered the pull out strength when evaluating the stability of temporary screws [43-46]. This parameter is a complementary indicator of primary stability, apart from placement torque. Although a complete simulation of biomechanics involved during clinical routine is not possible, the attempt to mimic dynamic load cycles under angulation, can efficiently commute axial pull out forces into component with shear behavior. The same approach was reported by $\mathrm{Xu}$ et al. during evaluations of angulated temporary screw stability in dogs [47]. In this work, Xu et al. reported that slight angulated temporary screws demonstrated an enhanced stability compared to vertical or extremely tilted screws. The results of this present work support the development of our dynamic model loaded by pulling forces applied under angles between $10^{\circ}$ and $15^{\circ}$ [47].

\section{Conclusions}

The stability of temporary screws after dentary and orthopedic forces under static and dynamic loads allows for the following conclusions: 
- Limited influence in screws primary stability were identified by static loads applied by $2 \mathrm{~N}$ forces (dentary forces), although $5 \mathrm{~N}$ loads (orthopedic forces) had produced significant influence in stability loss;

- Dynamic loads applied under 56,000 cycles showed relevant influence in screw stability loss after paired comparisons;

- The magnitude of dynamic loads had limited impact into torque peak values, being the type of load significant in primary stability changes. Intermittent forces (dynamic cycles) had relevant effects onto stability loss of temporary screws.

Acknowledgments: We thank Carlos Chagas Filho Foundation for Research Support from the Rio de Janeiro State (FAPERJ) and Capes Foundation from Brazilian Government for support this investigation by the grants: E-26/102.766/2012, BEX 539012-5/2013, Universal 476757/2012-6, E-26/201.759/2015, E-26/201.828/2015, E-26/010.001.262/2015, and 449472-2014-0.

Author Contributions: Flavia A. Barbosa executed experiments, Ligia M. Ferreira assisted in clinical issues and into results analysis, Daniel J. Fernandes and Carlos N. Elias have conceived and designed the experiments, interpreted results, wrote, revised, and corrected the manuscript.

Conflicts of Interest: The authors declare no conflict of interest.

\section{References}

1. Mihara, H.; Cheng, B.C.; David, S.M.; Ohnari, K.; Zdeblick, T.A. Biomechanical comparison of posterior cervical fixation. Spine 2001, 26, 1662-1667. [CrossRef] [PubMed]

2. Calvert, G.C.; Lawrence, B.D.; Abtahi, A.M.; Bachus, K.N.; Brodke, D.S. Cortical screws used to rescue failed lumbar pedicle screw construct: A biomechanical analysis. J. Neurosurg. Spine 2015, 22, 166-172. [CrossRef] [PubMed]

3. Elias, C.N.; Ruellas, A.C.O.; Fernandes, D.J. Orthodontic implants: Concepts for the orthodontic practitioner. Int. J. Dent. 2012, 2012, e1-e7. [CrossRef] [PubMed]

4. Chang, J.Z.; Chen, Y.; Tung, Y.; Chiang, Y.; Lai, E.H.; Chen, W.; Lin, C. Effects of thread depth, taper shape, and taper length on the mechanical properties of mini-implants. Am. J. Orthod. Dentofac. Orthop. 2012, 141, 279-288. [CrossRef] [PubMed]

5. Tabuchi, M. ; Ikeda, T; Nakagawa, K.; Hirota, M.; Park, W.; Miyazawa, K.; Goto, S.; Ogawa, T. Ultraviolet photofunctionalization increases removal torque values and horizontal stability of orthodontic miniscrews. Am. J. Orthod. Dentofac. Orthop. 2015, 148, 274-282. [CrossRef] [PubMed]

6. Lekholm, U.; Zarb, G.A. Patient selection and preparation. In Tissue Integrated Prostheses: Osseointegration in Clinical Dentistry, 1st ed.; Zarb, G.A., Albrektsson, T., Branemark, P.I., Eds.; Quintessence: Chicago, IL, USA, 1985; pp. 199-209.

7. Alrbata, R.H.; Yu, W.; Kyung, H. Biomechanical effectiveness of cortical bone thickness on orthodontic microimplant stability: An evaluation based on the load share between cortical and cancellous bone. Am. J. Orthod. Dentofac. Orthop. 2014, 146, 175-182. [CrossRef] [PubMed]

8. Cunha, A.C.; Marquezan, M.; Lima, I.; Lopes, R.T.; Nojima, L.I.; Sant'Anna, E.F. Influence of bone architecture on the primary stability of different mini-implant designs. Am. J. Orthod. Dentofac. Orthop. 2015, 147, 45-51. [CrossRef] [PubMed]

9. Fernandes, D.J.; Elias, C.N.; Ruellas, A.C.O. Influence of screw length and bone thickness on the stability of temporary implants. Materials 2015, 8, 6558-6569. [CrossRef]

10. Farnsworth, D.; Rossouw, P.E.; Ceen, R.F.; Buschang, P.H. Cortical bone thickness at common miniscrew implant placement sites. Am. J. Orthod. Dentofac. Orthop. 2011, 139, 495-503. [CrossRef] [PubMed]

11. Migliorati, M.; Signori, A.; Biavati, S. Temporary anchorage device stability: An evaluation of thread shape factor. Eur. J. Orthod. 2012, 34, 582-586. [CrossRef] [PubMed]

12. Brettin, B.T.; Grosland, N.M.; Qian, F.; Southard, K.A.; Stuntz, T.D.; Morgan, T.A.; Marshall, S.D.; Southard, T.E. Bicortical vs monocortical orthodontic skeletal anchorage. Am. J. Orthod. Dentofac. Orthop. 2008, 134, 625-635. [CrossRef] [PubMed]

13. Ozdemir, F.; Tozlu, M.; Germec-Cakan, D. Cortical bone thickness of the alveolar process measured with cone-beam computed tomography in patients with different facial types. Am. J. Orthod. Dentofac. Orthop. 2013, 143, 190-196. [CrossRef] [PubMed] 
14. Yoo, S.; Park, Y.; Hwang, C.; Kim, J.; Choi, E.; Cha, J. A comparison of tapered and cylindrical miniscrew stability. Eur. J. Orthod. 2014, 36, 557-562. [CrossRef] [PubMed]

15. Suzuki, E.Y.; Suzuki, B. Placement and removal torque values of orthodontic miniscrew implants. Am. J. Orthod. Dentofac. Orthop. 2011, 139, 669-678. [CrossRef] [PubMed]

16. Cha, J.; Hwang, C.; Kwon, S.H.; Jung, H.; Kim, K.; Yu, H.S. Strain of bone-implant interface and insertion torque regarding different miniscrew thread designs using an artificial bone model. Eur. J. Orthod. 2015, 37, 268-274. [CrossRef] [PubMed]

17. Lim, H.; Choi, Y.; Evans, C.A.; Hwang, H.S. Predictors of initial stability of orthodontic miniscrew implants. Eur. J. Orthod. 2011, 33, 528-532. [CrossRef] [PubMed]

18. McManus, M.M.; Qian, F.; Grosland, N.M.; Marshall, S.D.; Southard, T.E. Effect of miniscrew placement torque on resistance to miniscrew movement under load. Am. J. Orthod. Dentofac. Orthop. 2011, 140, e93-e98. [CrossRef] [PubMed]

19. Barbosa, F.A.; Barboza, A.; Fernandes, D.J.; Elias, C.N. Stability of temporary orthodontic implants after dynamic load cycles. Int. J. Oral Dent. Health 2016, 2, 35-39. [CrossRef]

20. Reynders, R.; Ronchi, L.; Bipat, S. Mini-implants in orthodontics: A systematic review of the literature. Am. J. Orthod. Dentofac. Orthop. 2009, 135, 564.e1-564.e9. [CrossRef]

21. Camey, L.O.; Campbell, P.M.; Spears, R.; Ceen, R.F.; Melo, A.C.; Buschang, P.H. Effects of pilot holes on longitudinal miniscrew stability and bony adaptation. Am. J. Orthod. Dentofac. Orthop. 2014, 146, 554-564.

22. Suzuki, M.; Deguchi, T.; Watanabe, H.; Seiryu, M.; Likubo, M.; Sasano, T.; Fujiyama, K.; Takano-Yamamoto, T. Evaluation of optimal length and insertion torque for miniscrews. Am. J. Orthod. Dentofac. Orthop. 2013, 144, 251-259. [CrossRef] [PubMed]

23. Inonue, M.; Kuroda, S.; Yasue, A.; Horiuchi, S.; Kyung, H.; Tanaka, E. Torque ratio as a predictable factor on primary stability of orthodontic miniscrew implants. Implant Dent. 2014, 23, 576-581.

24. Santos, R.F.; Ruellas, A.C.O.; Fernandes, D.J.; Elias, C.N. Insertion torque versus mechanical resistance of mini-implants inserted in different cortical thickness. Dent. Press J. Orthod. 2014, 19, 90-94. [CrossRef]

25. Vilani, G.N.L.; Ruellas, A.C.O.; Mattos, C.T.; Fernandes, D.J.; Elias, C.N. Influence of cortical thickness on the stability of mini-implants with microthreads. Braz. Oral. Res. 2015, 29, e1-e7. [CrossRef] [PubMed]

26. El-Dawlatly, M.M.; Abou-EL-Ezz, A.M.; El-Sharaby, F.A.; Mostafa, Y.A. Zygomatic mini-implant for Class II correction in growing patients. J. Orofac. Orthop. 2014, 75, 213-225. [CrossRef] [PubMed]

27. Kim, G.T.; Kim, S.H.; Choi, Y.S.; Park, Y.J.; Chung, K.R.; Suk, K.E.; Choo, H.; Huang, J.C. Cone-beam computed tomography evaluation of orthodontic miniplate anchoring screws in the posterior maxilla. Am. J. Orthod. Dentofac. Orthop. 2009, 136, 628.e1-628.e10. [CrossRef]

28. Woodall, N.; Tadepalli, S.C.; Qian, F.; Grosland, N.M.; Marshall, S.D.; Southard, T.E. Effect of miniscrew angulation on anchorage resistance. Am. J. Orthod. Dentofac. Orthop. 2011, 139, e147-e152. [CrossRef] [PubMed]

29. Motoyoshi, M.; Yoshida, T.; Ono, A.; Shimizu, N. Effect of cortical bone thickness and implant placement torque on stability of orthodontic mini-implants. Int. J. Oral. Maxillofac. Implants 2007, 22, 779-784. [PubMed]

30. Oliscovicz, N.F.; Shimano, A.C.; Marcantonio Junior, É.; Lepri, C.P.; Dos Reis, A.C. Analysis of primary stability of dental implants inserted in different substrates using the pullout test and insertion torque. Int. J. Dent. 2013, 2013, e1-e5. [CrossRef] [PubMed]

31. Uemera, M.; Motoyoshi, M.; Yano, S.; Sakaguchi, M.; Igarashi, Y.; Shimizu, N. Orthodontic mini-implant stability and the ratio of pilot hole implant diameter. Eur. J. Orthod. 2012, 34, 52-56. [CrossRef] [PubMed]

32. Cho, K.C.; Baek, S.H. Effects of predrilling depth and implant shape on the mechanical properties of orthodontic mini-implants during the insertion procedure. Angle Orthod. 2012, 82, 618-624. [CrossRef] [PubMed]

33. Son, S.; Motoyoshi, M.; Uchida, Y.; Shimizu, N. Comparative study of the primary stability of self-drilling and self-tapping orthodontic miniscrews. Am. J. Orthod. Dentofac. Orthop. 2014, 145, 480-485. [CrossRef] [PubMed]

34. Shin, Y.; Ahn, H.; Park, Y.; Kim, S.; Chung, K.; Cho, I.; Nelson, G. Effects of predrilling on the osseointegration potential of mini-implants. Angle Orthod. 2012, 82, 1008-1013. [CrossRef] [PubMed]

35. Esenlik, E.; Aglarci, C.; Albayrak, G.E.; Findik, Y. Maxillary protraction using skeletal anchorage and intermaxillary elastics in Skeletal Class III patients. Korean J. Orthod. 2015. [CrossRef] [PubMed] 
36. Armstrong, M.M. Coiled Wire Spring Appliances for Use in Orthodontics. U.S. Patent 3,618,214 A, 4 May 1970.

37. Lewis-Klapper, R.G. Orthodontic device for correcting overbite and underbite. U.S. Patent 5,846,074 A, 8 December 1998.

38. Brown, R.N.; Sexton, B.E.; Chu, T.G.; Katona, T.R.; Stewart, K.T.; Kyung, H.; Liu, S.S. Comparison of stainless steel and titanium alloy orthodontic miniscrew implants: A mechanical and histologic analysis. Am. J. Orthod. Dentofac. Orthop. 2014, 145, 496-504. [CrossRef] [PubMed]

39. Catharino, P.C.C.; Dominguez, G.C.; Pinto, D.S., Jr.; Morea, C. Histologic, histomorphometric, and radiographic monitoring of bone healing around in-office-sterilized orthodontic mini-implants with or without immediate load: Study in rabbit tibiae. Int. J. Oral. Maxillofac. Implants 2014, 29, 321-330. [CrossRef] [PubMed]

40. Chen, Y.; Shin, H.; Kyung, H. Biomechanical and histological comparison of self-drilling and self-tapping orthodontic microimplants in dogs. Am. J. Orthod. Dentofac. Orthop. 2008, 133, 44-50. [CrossRef] [PubMed]

41. Çehreli, S.; Arman-Ozçirpici, A. Primary stability and histomorphometric bone-implant contact of self-drilling and self-tapping orthodontic microimplants. Am. J. Orthod. Dentofac. Orthop. 2012, 141, 187-195. [CrossRef] [PubMed]

42. Largura, L.Z.; Argenta, M.A.; Sakima, M.T.; Camargo, E.S.; Guariza-Filho, O.; Tanaka, O.M. Bone stress and strain after use of a miniplate for molar protraction and uprighting: A 3-dimensional finite element analysis. Am. J. Orthod. Dentofac. Orthop. 2014, 146, 198-206. [CrossRef] [PubMed]

43. Ferrara, L.A.; Ryken, T.C. Screw Pullout Testing. In Mechanical Testing of Bone and the Bone-Implant Interface, 1st ed.; Draughn, R.A., An, Y.H., Eds.; CRC Press: Boca Raton, FL, USA, 2000; pp. 551-566.

44. Wu, J.H.; Wang, H.C.; Chen, C.M.; Lu, P.C.; Lai, S.T.; Lee, K.T.; Du, J.K. Pullout strengths of orthodontic palatal mini-implants tested in vitro. J. Dent. Sci. 2011, 6, 200-204. [CrossRef]

45. Crum, M.S.; Young, F.A.; An, Y.H. Screw pullout test for evaluating mechanical properties of bone. In Mechanical Testing of Bone and the Bone-Implant Interface, 1st ed.; Draughn, R.A., An, Y.H., Eds.; CRC Press: Boca Raton, FL, USA, 2000; pp. 321-328.

46. Huja, S.S.; Litsky, A.S.; Beck, F.M.; Johnson, K.A.; Larsen, P.E. Pull-out strength of monocortical screws placed in the maxillae and mandibles of dogs. Am. J. Orthod. Dentofac. Orthop. 2005, 127, 307-313. [CrossRef] [PubMed]

47. Xu, Z.; Wu, Y.; Zhao, L.; Zhou, Y.; Wei, X.; Tang, N.; Feng, X.; Tang, T.; Zhao, Z. Effect of placement angle on the stability of loaded titanium microscrews in beagle jaws. Angle Orthod. 2013, 83, 659-666. [CrossRef] [PubMed]

(C) 2017 by the authors. Licensee MDPI, Basel, Switzerland. This article is an open access article distributed under the terms and conditions of the Creative Commons Attribution (CC BY) license (http:/ / creativecommons.org/licenses/by/4.0/). 